DOI: $10.17805 /$ trudy.2018.6.3

\title{
КОМСОМОЛ В УПРАВЛЕНИИ ПРОИЗВОДСТВОМ
}

\author{
Е. П. Володина \\ Московский гуманитарный университет
}

Аннотация: В статье рассматриваются вопросы участия комсомольцев и молодежи 21 предприятия станкостроительной отрасли СССР в управлении производством. Материалами выступили неопубликованные данные исследования 1972-1974 г2. с участием автора статьи.

Ключевые слова: ВЛСКМ; комсомол; станкостроительная отрасль; управление производством; опрос; история СССР

\section{KOMSOMOL IN PRODUCTION CONTROL}

\author{
E. P. Volodina
}

\section{Moscow University for the Humanities}

Аннотация: The paper considers the issues of Komsomol and youth from 21 machine building plants of the USSR participating in production control. It is based on unpublished data of the 1972-1974 research featuring the author of the paper.

Ключевые слова: All-Union Leninist Young Communist League; Komsomol; machine building industry; production control; survey; history of the USSR

В Высшей комсомольской школе при ЦК ВЛКСМ я начала работать с 20 сентября 1969 года. Полтора месяца - в приемной комиссии. Возглавляла ее Сергутина Юлия Николаевна. Оформляли первый набор на факультет истории и коммунистического воспитания. Все республиканские и областные комитеты комсомола были представлены 105 первыми абитуриентами. Среди них были Плаксий Сергей Иванович (ныне ректор Национального института бизнеса, г. Москва), Никулин Василий Гаврилович (был проректором Института молодежи). Я помню, как все приехавшие волновались потому, что у некоторых, в частности рекомендованных от армии и флота, не было достаточно времени, чтобы подготовиться к вступительным экзаменам. Как отговаривали Валерия Зорина не уезжать после первого экзамена, оценку которого он посчитал непроходной. Помню Айкуш Галстян из Армении. Она привлекла мое внимание своей незаурядностью, притяга- 
Научные труды Московского гуманитарного университета 2018 № 6

тельностью. Я думала, вот такой и должна быть идеальная комсомолка. Большой опыт работы в комсомоле - первый секретарь комитета комсомола педагогического училища, после окончания два года освобожденным секретарем того же училища: веселая, задорная, общительная, с отличным голосом, душа компании. И вот она не прошла собеседование. Как она рассказывала, комиссии не очень понравилось то, что она занималась вокалом и то, что она поступала, но не прошла по конкурсу в Университет Дружбы народов. Но Айкуш не мыслила себя без комсомола. Было принято решение, поскольку Армения была представлена двумя кандидатами, дать им право выбора: один остается на учебу, второй уезжает домой. Второй абитуриент, молодой человек, добровольно уступил место Айкуш, считая, что для комсомола она подходит больше, чем он, и уехал. За четыре года, проведенные в ВКШ, Айкуш активно занималась общественной работой. Она получила диплом с отличием и была рекомендована для ответственной идеологической комсомольской работы. Это лишь две истории, у каждого из 105 кандидатов история была своя.

По окончании работы приемной комиссии я год проработала старшим лаборантом на кафедре иностранных языков, а с 1970 г. - в лаборатории конкретных социологических исследований.

Первое социологическое исследование под рабочим названием «Общественные формы управления производством», в котором я принимала участие, я помню, как будто это было вчера, хотя проводилось оно в 19721974 гг. Уже в должности младшего научного сотрудника я входила в группу социологов ЛКСИ ВКШ при ЦК ВЛКСМ. Ее полный состав: В. И. Мухачев (руководитель), В. С. Боровик, А. И. Ефимова, Е. П. Володина, Е. Е. Леванов, М. Ф. Фатхуллин, В.Т. Цыба, А.Л. Бражко.

Объектами исследования было выбрано 21 предприятие станкостроительной отрасли:

- Алма-Атинский станкостроительный «20 лет Октября»,

- Вильнюсский станкостроительный завод «Комунарас»,

- Гомельский завод нормализованных узлов,

- Егорьевский станкостроительный завод «Комсомолец»,

- Иркутский станкостроительный завод,

- Кимрский станкостроительный завод,

- Краматорский завод тяжелого станкостроения имени В. Я. Чубаря,

- Краснодарский станкостроительный завод имени Г. М. Седина,

- Минский станкостроительный завод имени Октябрьской революции,

- Московский завод координатно-расточных станков,

- Мукачевский станкостроительный завод имени С. М. Кирова,

- Одесский завод фрезерных станков имени С. М. Кирова, 
- Оренбургский завод «Гидропресс»,

- Саратовский станкостроительный завод,

- Скопинский завод электронасосов,

- Тбилисский станкостроительный завод имени С. М. Кирова,

- Троицкий станкостроительный завод,

- Ульяновский завод тяжелых и уникальных станков,

- Хабаровский станкостроительный завод,

- Чаренцаванский завод расточных станков,

- Читинский станкостроительный завод.

В ходе исследования применялись методы изучения текущих архивов производственных коллективов, систематизации статистических материалов, опрос экспертов и анкетирование. Всего было опрошено 8000 рабочих и 900 ИТР на основе представительной выборки ${ }^{1}$.

В мои обязанности входило участие в сборе информации и в ее обработке. Я совместно со старшими научными сотрудниками проводила анкетирование, интервьюирование и сбор информации по пяти заводам: Егорьевскому, Ульяновскому, Московскому, Саратовскому и Чаренцаванскому.

К великому сожалению, это исследование не привлекло внимания широкой научной общественности в силу того, что отчет был представлен в отдел рабочей молодежи ЦК ВЛКСМ и на те предприятия, где проводилось исследование. К счастью, некоторые аспиранты ВКШ использовали результаты этого исследования в своих диссертациях (Е. Е. Леванов, А. Л. Бражко и др.). Все участники рабочей группы в своих статьях в сборниках научных трудов и выступлениях на научно-практических конференциях также размещали результаты исследования. Но программы исследования и монографий издано не было.

В данной статье затрагивается лишь один из аспектов этого исследования, а именно - участие комсомольцев и молодежи вышеперечисленных предприятий в управлении производством, который ранее не выделялся в отдельный раздел отчета.

По переписи 1970 г. в стране молодежь до 30 лет составляла четверть всех горняков, около трети металлургов и литейщиков, более $45 \%$ машиностроителей и металлистов, около 60\% токарей, $60 \%$ фрезеровщиков (Итоги Всесоюзной ..., 1971: 448, 458). На 21 обследованном заводе членов ВЛКСМ насчитывалось 8258 чел., что составляло около 20 \% от общего числа работающих.

В эпоху развитого социализма под участием в управлении производством понималось: постоянно быть в курсе всей деятельности своего трудового коллектива, оказывать влияние на успешное выполнение планов,

${ }^{1}$ Здесь и далее приводятся данные по: Мухаев, 1979. 
Научные труды Московского гуманитарного университета 2018 № 6

производственных заданий, участвовать в обсуждении планов коллектива, социалистических обязательств, в подведении итогов его работы, а также вносить предложения, направленных на улучшение деятельности трудового коллектива. Участие в управлении производством подразумевало неотрывность от тесного взаимодействии с административно-хозяйственной системой управления предприятием.

К тому времени на советских производственных предприятиях сложилась система общественных органов управления. В эту систему входили:

a) выборные органы основных общественных организаций (партийной, профсоюзной, комсомольской) и их комиссии;

б) специальные общественные органы управления (постоянно действующие производственные совещания, народный контроль и «Комсомольский прожектор», общественные отделы кадров, бюро нормирования и экономического анализа, товарищеские суды и советы наставников, советы молодых рабочих и советы молодых специалистов, руководящие органы ВОИР и НТО и т. д.);

в) конференции, активы, собрания общественных организаций и производственных коллективов, если они рассматривали вопросы жизнедеятельности производственного коллектива.

Молодежь имела возможность участвовать в управлении через особые молодежные органы: комсомольскую организацию, «Комсомольский прожектор», советы молодых специалистов, советы молодых рабочих, молодежные общественные отделы кадров, комсомольские штабы качества и т. д. Нередко администрация предоставляла комсомольско-молодежным коллективам дополнительные права в области управления: принимать решения по вопросам комплектования бригад, выбирать бригадиров и мастеров и т. п.

Таблица 1. Общественные органы управления производством и их состав на 21 заводе станкостроительной отрасли (1972-1974 гг.)

\begin{tabular}{|c|c|c|c|c|c|}
\hline Наименование органов & $\begin{array}{c}\text { Коли- } \\
\text { чество } \\
\text { органов }\end{array}$ & $\begin{array}{c}\text { Число } \\
\text { членов в } \\
\text { них }\end{array}$ & $\begin{array}{c}\text { Члены } \\
\text { КПСС и } \\
\text { канд. }\end{array}$ & $\begin{array}{c}\text { Члены } \\
\text { ВЛКСМ }\end{array}$ & $\begin{array}{c}\text { Беспар- } \\
\text { тийные }\end{array}$ \\
\hline Парткомы (бюро) & 186 & $\begin{array}{c}1938 \\
100 \%\end{array}$ & $\begin{array}{c}1938 \\
100\end{array}$ & - & - \\
\hline $\begin{array}{c}\text { Фабрично-заводские местные } \\
\text { комитеты (бюро) }\end{array}$ & 354 & $\begin{array}{c}4930 \\
100 \%\end{array}$ & $\begin{array}{c}1248 \\
25,3\end{array}$ & $\begin{array}{c}602 \\
12,2\end{array}$ & 308062,5 \\
\hline $\begin{array}{c}\text { Комитеты ВЛКСМ (бюро) } \\
\text { Постоянно действующее производ- } \\
\text { ственное совещание (ПдПС) }\end{array}$ & 75 & $\begin{array}{c}1912 \\
100 \%\end{array}$ & $\begin{array}{c}445 \\
23,3\end{array}$ & $\begin{array}{c}1467 \\
76,7\end{array}$ & - \\
\hline
\end{tabular}




\begin{tabular}{|c|c|c|c|c|c|}
\hline Народный контроль & 354 & $\begin{array}{c}3216 \\
100 \%\end{array}$ & $\begin{array}{c}1388 \\
43,1\end{array}$ & 35110,9 & $\begin{array}{c}1477 \\
46,0 \\
\end{array}$ \\
\hline «Комсомольский прожектор» & 321 & $\begin{array}{l}1223 \\
100 \% \\
\end{array}$ & 12810,5 & 109489,5 & 1 \\
\hline $\begin{array}{c}\text { Общественные бюро экономического } \\
\text { анализа } \\
\end{array}$ & 20 & $\begin{array}{c}143 \\
100 \% \\
\end{array}$ & $\begin{array}{c}49 \\
34,3 \\
\end{array}$ & 2517,5 & $\begin{array}{c}69 \\
48,2 \\
\end{array}$ \\
\hline Общественные бюро нормирования & 57 & $\begin{array}{c}309 \\
100 \%\end{array}$ & $\begin{array}{c}94 \\
30,4\end{array}$ & $\begin{array}{l}30 \\
9,7\end{array}$ & $\begin{array}{l}185 \\
59,9\end{array}$ \\
\hline Общественные отделы кадров & 201 & $\begin{array}{l}1169 \\
100 \%\end{array}$ & $\begin{array}{l}340 \\
29,1\end{array}$ & $\begin{array}{l}82 \\
7,1\end{array}$ & $\begin{array}{l}747 \\
63,8\end{array}$ \\
\hline Совет молодых рабочих & 3 & $\begin{array}{c}24 \\
100 \% \\
\end{array}$ & & $\begin{array}{c}21 \\
87,5\end{array}$ & $\begin{array}{c}3 \\
12,5 \\
\end{array}$ \\
\hline Совет молодых специалистов & 14 & $\begin{array}{c}183 \\
100 \%\end{array}$ & $\begin{array}{c}22 \\
12,0\end{array}$ & $\begin{array}{l}125 \\
68,3\end{array}$ & $\begin{array}{c}36 \\
19,7\end{array}$ \\
\hline Товарищеский суд & 78 & $\begin{array}{c}394 \\
100 \%\end{array}$ & $\begin{array}{l}155 \\
39,3\end{array}$ & $\begin{array}{l}32 \\
8,1\end{array}$ & $\begin{array}{l}207 \\
52,6\end{array}$ \\
\hline Итого в абс. & 2042 & 18584 & 7125 & 4085 & 7374 \\
\hline Итого в \% & & $100 \%$ & 38,3 & 22,0 & 39,7 \\
\hline Всего работало на 21 заводе в абс. & - & 43293 & 6314 & 8258 & 28721 \\
\hline Всего работало на 21 заводе в \% & & $100 \%$ & 14,6 & 19,1 & 66,3 \\
\hline
\end{tabular}

На изученных предприятиях доля комсомольцев, входящих в такие общественные органы как комитеты (бюро) ВЛКСМ, «Комсомольский прожектор», советы молодых рабочих, советы молодых специалистов колебалась от 68 до 90\% от общего числа членов этих органов. А в то же время в постоянно действующих производственных совещаниях, в общественных отделах кадров, в народном контроле, в профсоюзных органах, общественных бюро нормирования, товарищеских судах доля молодежи была от 7 до $12 \%$ (см. таблицу 1$)$.

Общее руководство общественными формами управления осуществляла партийная организация. Партийная организация предприятия и ее руководящие органы несли ответственность вместе с администрацией за деятельность коллектива, за функционирование и развитие предприятия. В соответствии с Уставом КПСС первичным партийным организациям было предоставлено право контроля за деятельностью администрации. Это положение нашло отражение и в законодательстве, регулирующем деятельность производственных объединений и предприятий.

Определяющая роль партийной организации в общественном управ- 
Научные труды Московского гуманитарного университета 2018 № 6

лении предприятий становилась особенно очевидной, если учесть ведущее место коммунистов в общественных органах управления. Так, на 21 предприятии станкостроения среди членов всех этих органов коммунисты составляли почти 40\%, в то время как доля их в коллективах - около $15 \%$ (см. таблицу 1).

Важное место в осуществлении общественных начал в производственных коллективах принадлежала профсоюзным организациям, их руководящим органам в трудовых коллективах. С самого начала социалистических преобразований в нашей стране профессиональные союзы играли важнейшую роль в системе политической организации социалистического общества, в воспитании трудящихся, а, следовательно, и в управлении обществом, в управлении общественным производством.

Для выполнения стоящих перед ними задач профсоюзы были наделены большими правами и полномочиями, закрепленными советским законодательством. Дальнейшее расширение прав профсоюзов в управлении делами трудовых коллективов нашло отражение в Положении о правах фабричного, заводского, местного комитета профессионального союза, утвержденного Президиумом Верховного Совета СССР 27 сентября 1971 г.

В Положении подчеркивалось, что комитет профсоюза «обеспечивает рабочим и служащим участие в управлении производством через общие собрания, производственные совещания, конференции и различные формы общественной самодеятельности рабочих и служащих.

Администрация предприятий, учреждений, организаций была обязана создавать условия, обеспечивающие участие рабочих и служащих в управлении производством. Должностные лица предприятий, учреждений, организаций обязывались своевременно рассматривать критические замечания и предложения рабочих и служащих и сообщать им о принятых мерах» (Справочник ..., 1973: 137).

Фабрично-заводские местные комитеты (ФЗМК) участвовали в разработке проектов производственных планов и планов внедрения новой техники, планов капитального строительства предприятия, жилых домов и культурно-бытовых объектов, а также планов социального развития коллектива. От имени коллектива рабочих и служащих ФЗМК заключали коллективный договор с администрацией и осуществляли контроль за его выполнением. Администрация только совместно с ФЗМК могла решать вопросы распределения фондов предприятия.

Лишь по согласованию с ФЗМК администрация могла утвердить правила внутреннего распорядка, установить систему оплаты, внести и пересмотреть нормы выработки, разрешить совмещение, установить очередность отпусков, утвердить графики сменности, принять на работу подростков и т. 
д. ФЗМК осуществляли контроль за выполнением решений собраний и конференций рабочих и служащих, постоянно действующих производственных совещаний, за выполнением законодательства о труде, правил и норм по технике безопасности, производственной санитарии и т. д. Распределение и предоставление жилья рабочим и служащим предприятия производилось совместным решением комитета профсоюзов и администрации.

Фабрично-заводские местные комитеты имели право заслушивать доклады руководителей предприятия, учреждения, организации о выполнении производственного плана, о выполнении обязательств по коллективному договору, по организации и улучшению условий труда, материальному и культурно-бытовому обслуживанию, требовать устранения выявленных недостатков.

Даже простое перечисление основных прав профсоюзного комитета показывает, какие огромные и серьезные возможности имели профсоюзы в области управления производством и привлечения всех членов коллектива к управлению. Среди 4930 членов ФЗМК на 21 предприятии станкостроения 602 члена ВЛКСМ (12,2\% к общему числу членов ФЗМК) (см. таблицу 1).

Профсоюзные организации и их комитеты осуществляли на предприятиях руководство большинством общественных органов, создаваемых в коллективе специально для управления теми или иными сторонами производства, жизнедеятельности трудового коллектива (ПДПС, общественные бюро экономического анализа и бюро нормирования, общественные отделы кадров, советы НТО и советы ВОИР и т. д.).

Важнейшее место среди органов общественного управления занимали постоянно действующие производственные совещания, которым по Положению, утвержденному в июне 1973 г. Советом Министров СССР и ВЦСПС, были предоставлены широкие права. Являясь совещательным органом, производственные совещания вырабатывали рекомендации, предложения, которые администрация, в соответствии с Положением, была обязана рассматривать в короткие сроки, устраняя указанные недостатки, используя предложения совещаний для улучшения работы совещаний. В ПДПС из 3054 членов, принятых за 100\%, 217 человек (или 7,1\%) - члены ВЛКСМ (см. таблицу 1).

Менее массовыми, но не менее эффективными общественными органами управления являлись общественные бюро экономического анализа и бюро нормирования, в них комсомольцы составляли соответственно 17,5 и 9,7 \% (см. таблицу 1). Значительный эффект давала практика совместной деятельности общественных бюро нормирования и экономических служб предприятий.

Одной из наиболее массовых и эффективных форм общественного 
Научные труды Московского гуманитарного университета 2018 № 6

управления производством являлись группы и посты народного контроля на предприятиях - низовое звено единой системы народного контроля страны, возглавляемой Комитетом народного контроля при Совете Министров СССР.

Заводские и цеховые группы народного контроля 21 предприятия станкостроения, а в них было представлено около 11 \% комсомольцев (см. таблицу 1), в соответствии с представленными им правами осуществляли одну из важнейших функций управления - контроль за исполнением решений. В ходе общественной контрольной деятельности народные контролеры вели борьбу за бережливость, экономию энергетических ресурсов, сырья, материалов и рабочего времени. Характерной чертой работы групп народного контроля являлась организационная работа по устранению отмеченных недостатков и их профилактика.

Большую работу по привлечению к управлению рабочей молодежи вели на предприятиях комсомольские организации и их руководящие органы. XVII съезд ВЛКСМ включил в Устав Всесоюзного Ленинского Союза Молодежи новый пункт: «Первичная комсомольская организация активно участвует в жизни трудового коллектива - основной ячейки социалистического общества, воспитывает у комсомольцев и молодежи коммунистическое отношение к труду, к общественному достоянию, чувство коллективизма, прививает молодежи навыки управления общественными и государственными делами...» (XVII съезд ..., 1974: 203).

Молодежи 21 предприятия станкостроительной отрасли не только представлялись равные со старшими поколениями права для участия в управлении производством, но давалась возможность участвовать в управлении через особые молодежные органы: «Комсомольский прожектор» (89,5\% комсомольцев), советы молодых специалистов $(68,3 \%)$, советы молодых рабочих $(87,5 \%)$ и т. д. (см. таблицу 1$)$.

Нередко администрация предоставляла комсомольско-молодежным коллективам дополнительные права в области управления: принимать решения по вопросам комплектования бригад, выбирать бригадиров и мастеров и т. п.

Молодые рабочие, специалисты, служащие, принимая участие в работе органов общественных организаций и в специальных органах общественного управления, в работе собраний и конференций, внося предложения по улучшению работы, практически включались в подготовку и принятие управленческих решений и контроль за их исполнением, т. е. участвовали в управлении делами своего коллектива.

Особое место в привлечении молодежи к управлению производством занимали штабы и посты «Комсомольского прожектора». Прежде всего 
«Комсомольский прожектор» - специфическая молодежно-комсомольская форма общественного контроля, входящая в единую систему социалистического контроля страны. Огни «Комсомольского прожектора» - наследника лучших традиций «легкой кавалерии», зажглись в начале шестидесятых годов. «Комсомольский прожектор» являлся самой массовой и доступной формой участия молодежи в управлении. Не случайно в ее рядах насчитывалось более 3,5 млн юношей и девушек. Эту замечательную школу управления прошли многие миллионы комсомольцев и представителей несоюзной молодежи страны.

В рейдах, смотрах, проверках, проводимых «Комсомольским прожектором» вместе с членами его штабов и отрядов, участвовали большие группы комсомольцев и несоюзной молодежи. Таким образом, число молодежи, участвующей в работе «КП», значительно больше 3,5 млн. Так, во Всесоюзном общественном смотре использования резервов производства, который по призыву ВЦСПС и ЦК ВЛКСМ проводился всю девятую пятилетку, участвовало 7 млн молодых тружеников, хотя застрельщиками смотра и выступали в первую очередь « прожектористы ».

В 1974 г. во Всесоюзном рейде «КП» по борьбе с потерями, за экономию и бережливость участвовало 3 млн 600 тыс. молодых тружеников. Предложения, внесенные в ходе рейда, позволили предприятиям страны сэкономить более 500 млн рублей.

Важнейшую роль в привлечении рабочих к управлению производством играли рабочие собрания и конференции, обсуждающие наиболее важные вопросы производства, и особенно вопросы социального развития трудовых коллективов. На этих собраниях и конференциях формировалось большинство общественных органов управления (избирались их члены), на них же обсуждались коллективные договоры и планы социального развития и ход их выполнения. Рабочие собрания, при правильной подготовке, соблюдении демократической процедуры, являлись не только эффективной школой управления для масс рабочих, но и действенным общественным органом управления делами предприятия.

Все рассмотренные общественные органы управления работали в тесном единстве с административно-хозяйственной системой управления предприятиями, которую возглавлял полномочный представитель государственного управления общественным производством - руководитель предприятия. Управляя предприятием на основе единоначалия, персональной ответственности за дела завода, фабрики, шахты, строительной организации и т. Д., руководитель был обязан в соответствии с политикой партии и государства, закрепленной советским законодательством, всячески содей- 
Научные труды Московского гуманитарного университета 2018 № 6

ствовать развитию общественных начал в управлении производством, вовлечению членов коллектива в решение его дел.

В ходе нашего исследования у всех директоров (их заместителей), у начальников цехов изучаемых заводов были взяты интервью с целью выяснения отношения руководителей к участию рабочих в управлении производством. Все опрошенные руководители предприятий и цехов единодушно отмечали необходимость привлечения рабочих к управлению, благотворное влияние на дела предприятия активного участия рабочих в решении насущных вопросов производства, в укреплении трудовой дисциплины и т. д.

«В моей 18-летней производственной практике, - заявил начальник производства Кимрского станкостроительного завода, — не было еще случая, чтобы я обратился к рабочим за помощью, за советом по вопросам выполнения программы, внедрения новой технологии и чтобы мне отказали, чтобы мы сообща не нашли наилучшего решения. Активное участие рабочих в управлении наилучшим образом мобилизует коллектив на решение вопросов производства».

На всех исследованных предприятиях станкостроения и других отраслей промышленности функционировали почти все рассмотренные нами общественные органы управления, хотя на некоторых из них отсутствовали советы молодых рабочих, общественные бюро нормирования и экономического анализа.

«Какой положительный опыт дала практика привлечения трудящихся к управлению производством в Вашем коллективе?» - такой вопрос задали мы представителям администрации, партийным, профсоюзным, комсомольским работникам, а также руководителям ПДПС, групп народного контроля, «Комсомольского прожектора» и других общественных организаций. Ответы на этот вопрос были очень конкретными. «Привлечение трудящихся к управлению,- пишет директор крупного станкостроительного завода, - повышает ответственность всего коллектива за работу предприятия, помогает вскрыть и использовать резервы производлства, совершенствовать организацию труда, укреплять трудовую дисциплину».

Электромонтер Минского станкостроительного завода имени Октябрьской революции, председатель цехового комитета считал, что «участие рабочих в постоянно действующих производственных совещаниях, в других органах общественного управления активно влияет на дела производства. Они лучше осведомлены о делах предприятия, следовательно, видят перспективу его развития. Это способствует повышению их ответственности за результаты труда всего коллектива, что, в свою очередь, содействует эффективному использованию внутренних резервов».

Содержание этих двух ответов во многом сходно: у директора завода 
и рабочего этого же предприятия одни мысли, одни заботы. Может быть, масштаб их забот различен, но оба они являются хозяевами своего предприятия.

Как видно из таблицы 1, во всех общественных органах управления 21 предприятием насчитывается 18584 члена. Среди них 22\% членов ВЛКСМ.

Какова же общая картина участия в управлении производством комсомольцев и рабочей молодежи до 30 лет? В среднем по 21 предприятию станкостроения в управлении производством участвовали 56,4\% комсомольцев. (См. таблицу 2).

Таблища 2. Членство в КПСС, ВЛКСМ и участие молодых рабочих в управлении производством (в \% к числу опрошенных) (1972-1974 г2.) ${ }^{2}$

\begin{tabular}{|c|c|c|c|c|c|}
\hline Рабочие до 30 лет & $\begin{array}{c}\text { Члены } \\
\text { КПСС }\end{array}$ & $\begin{array}{c}\text { Члены } \\
\text { ВЛКСМ }\end{array}$ & $\begin{array}{c}\text { Беспартий- } \\
\text { ные }\end{array}$ & $\begin{array}{c}\text { Нет } \\
\text { ответа }\end{array}$ & Всего \\
\hline Среди всех опрошенных & 7,3 & 53,0 & 38,0 & 1,7 & 100,0 \\
\hline $\begin{array}{c}\text { Среди участвующих в } \\
\text { управлении }\end{array}$ & 12,3 & 56,4 & 28,7 & 2,6 & 100,0 \\
\hline $\begin{array}{c}\text { Среди неучаствующих в } \\
\text { управлении }\end{array}$ & 3,3 & 50,3 & 44,8 & 1,6 & 100,0 \\
\hline $\begin{array}{c}\text { Участвуют в управлении в } \\
\text { каждой группе }\end{array}$ & 75,2 & 47,5 & 34,8 & - & 44,7 \\
\hline
\end{tabular}

Цифры, приведенные в таблице 2, убедительно показывают авангардную роль молодых рабочих-коммунистов в сфере общественного управления производством на обследованных предприятиях. Среди всех опрошенных молодых рабочих коммунисты составляют 7,3\%, а среди участвующих в управлении их доля возрастает до 12,3\%, три четверти членов КПСС активно включены в управленческую деятельность. Значительно более активны в этой деятельности и члены ВЛКСМ по сравнению с несоюзной молодежью: более половины комсомольцев участвовали в управлении и лишь третья часть несоюзной рабочей молодежи. Молодые рабочие коммунисты и комсомольцы составляли около 70\% молодых рабочих до 30 лет, участвующих в управлении.

Таблища 3. Распределение возрастных групп в связи с участием в управлении производством (в \% к опрошенным)

\begin{tabular}{|c|c|c|c|c|c|c|c|c|}
\hline $\begin{array}{c}\text { Рабочие до } \\
\text { Золет }\end{array}$ & $\begin{array}{c}16-17 \\
\text { лет }\end{array}$ & $\begin{array}{c}18-19 \\
\text { лет }\end{array}$ & $\begin{array}{c}20-22 \\
\text { года }\end{array}$ & $\begin{array}{c}23-25 \\
\text { лет }\end{array}$ & $\begin{array}{c}26-28 \\
\text { лет }\end{array}$ & $\begin{array}{c}29-30 \\
\text { лет }\end{array}$ & $\begin{array}{c}\text { Нет } \\
\text { ответа }\end{array}$ & Всего \\
\hline $\begin{array}{c}\text { Среди всех опро- } \\
\text { шенных }\end{array}$ & 5,7 & 10,9 & 23,6 & 29,2 & 17,8 & 10,7 & 2,1 & 100,0 \\
\hline $\begin{array}{c}\text { Среди участвую- } \\
\text { щих в управле- } \\
\text { нии }\end{array}$ & 3,9 & 8,7 & 22,2 & 31,1 & 21,0 & 11,2 & 1,9 & 100,0 \\
\hline \hline
\end{tabular}

${ }^{2}$ В таблицах 2 и 3 - данные опроса 4061 молодого рабочего. 
Научные труды Московского гуманитарного университета 2018 № 6

\begin{tabular}{|c|c|c|c|c|c|c|c|c|}
\hline $\begin{array}{c}\text { Среди неучаству- } \\
\text { ющих в управле- } \\
\text { нии }\end{array}$ & 7,2 & 12,6 & 24,0 & 27,7 & 15,1 & 10,3 & 3,1 & 100,0 \\
\hline $\begin{array}{c}\text { Участвуют в } \\
\text { управлении в ка- } \\
\text { ждой возрастной } \\
\text { группе }\end{array}$ & 30,1 & 35,8 & 42,2 & 47,5 & 52,8 & 47,1 & - & 44,7 \\
\hline
\end{tabular}

Данные таблицы 3 свидетельствуют о четкой тенденции роста активности в управлении производством пяти первых групп, т. е. от 16 до 28 лет: от группы к группе число активно участвующих в управлении возрастает на 5-7\%. Средний уровень активности был характерен для возраста в 2223 года, на границе принятых в исследовании возрастных групп. Наиболее низкий уровень участия наблюдался у младших возрастных групп: в 16-17 лет ниже среднего уровня на 15\% и в 18-19 лет - на 10\%. Эти возрастные группы составляли около 17\% всех молодых рабочих. Более высокий уровень участия был характерен для трех старших возрастных групп (от 23 до 30 лет). Эти группы охватывали уже 57,7\% всей рабочей молодежи. Наивысший уровень участия в управлении достигался в $26-28$ лет $(52,8 \%)$. Эта группа охватывала 17,8\% молодых рабочих.

Итак, среди участвующих в управлении производством было 56,4\% комсомольцев. Мало это или много? Конечно, много. Ведь тот факт, что почти половина рабочих и $80 \%$ ИТР систематически решали насущные вопросы производственных коллективов, а среди них более половины членов ВЛКСМ говорит о высоком развитии общественных начал в управлении производством в годы проведения исследования. Достигнутый в то время довольно высокий уровень не являлся пределом; имелись объективные условия для значительного сокращения разрыва в массовости участия между молодыми рабочими, с одной стороны, молодыми ИТР и рабочими старших возрастов - с другой.

Молодежь, объединенная во Всесоюзный Ленинский Коммунистический Союз Молодежи, (а в то время в его рядах было свыше 38 млн чел.) имела возможность пройти замечательную практическую школу управления общественными и производственными делами. «Рабочий, участвуя в управлении производством, понимает свою непосредственную причастность ко всему общенародному достоянию, несет ответственность за него. Участие в управлении делами завода позволяет рабочему чувствовать, что он является хозяином производства», — заявил один из руководителей Хабаровского станкостроительного завода.

После 1976 г. Лаборатория конкретных социологических исследований ВКШ при ЦК ВЛКСМ преобразовалась в Научно-исследовательский 
центр при Высшей комсомольской школе при ЦК ВЛКСМ. Научные сотрудники сектора рабочей молодежи отдела трудового воспитания работающей молодежи по заданиям ЦК ВЛКСМ провели достаточно много исследований, в том числе комплексные всесоюзные «Формирование достойной смены рабочего класса» и «Формирование достойной смены сельскохозяйственных тружеников», но, к сожалению, провести повторное исследование общественных форм управления производством с целью установления динамики через 10 и 20 лет, как предполагалось в его начале, не удалось. Состояние общественных органов управления на вышеперечисленных предприятиях в наше время скорее всего не исследуется. Тем ценнее вспомнить и не забывать, как это было благодаря комсомолу в 70-х годах прошлого века.

\section{СПИСОК ЛИТЕРАТУРЫ}

Мухачев, В. И. (1979) Учится управлять, управляя. Молодежь в управлении государственными и общественными делами. М. : Знание. 64 с.

Мухачев, В. И., Боровик, В. С. (1975) Рабочий класс и управление производством. М. : Политиздат. 64 с.

Итоги Всесоюзной переписи населения 1970 года (1971). М. T. VI.

Справочник профсоюзного работника (1973). М. : Профиздат.

XVII съезд Всесоюзного Ленинского Коммунистического Союза Молодежи 23-27 апреля 1974 года. Стенографический отчет (1974). М. : Молодая гвардия. Т. 2.

Дата поступления: 30.08.2018 2.

Володина Елена Павловна - заведующая архивом Управления персоналом Московского гуманитарного университета. Адрес: 111395, Россия, г. Москва, ул. Юности, д. 5. Тел.: +7 (499) 374-57-40. Эл. адрес: evolodina@ mosgu.ru

Volodina Elena Pavlovna, Head, Human Resources Archive, Moscow University for the Humanities. Postal address: 5, Yunosti St., Moscow, Russian Federation, 111395. E-mail: evolodina@mosgu.ru

\section{Для цитирования:}

Володина Е. П. Комсомол в управлении производством [Электронный ресурс] // Научные труды Московского гуманитарного университета. 2018. № 6. URL: http://journals.mosgu.ru/trudy/article/view/834 (дата обращения: дд.мм.гг.). DOI: 10.17805/trudy.2018.6.3 